\title{
Agências de comunicação digital no Rio Grande do Sul: posicionamento das empresas-clientes
}

Digital communication agencies in Rio Grande do Sul, Brazil: positioning strategies of client companies

Agencias de comunicación digital en Rio Grande do Sul, Brasil: posicionamiento de las empresas-clientes

- Doutora em Comunicação pela Universidade Federal de Santa Maria (UFSM).

- Mestre em Comunicação pela UFSM.

- Membro dos Grupos de Pesquisa Comunicação Institucional e Organizacional e Práticas de Relações Públicas em suportes midiáticos digitais - CNPq/UFSM.

- Graduada em Comunicação Social - Relações Públicas, pela UFSM.

- Professora do Departamento de Comunicação da Faculdade de Biblioteconomia e Comunicação da Universidade Federal do Rio Grande do Sul (UFRGS).

- E-mail: elisangela.lasta@ufrgs.br 


\section{Resumo}

Este artigo tem como objetivo identificar as estratégias de posicionamento na rede empreendidas pelas agências que prestam serviços de produção de conteúdo digital no mercado corporativo do Rio Grande do Sul para seus clientes. Como metodologia, utilizou-se a análise estrutural das redes sociais. Desse modo, foram encontradas estratégias de: 1. posição de centralidade; 2. posição de intermediário; 3. posição de melhor PageRank; 4) posição tanto de intermediário como de melhor PageRank, e 5. posição de presença.

PALAVRAS-CHAVE: AMBIENTES DIGITAIS • ESTRATÉGIAS DE POSICIONAMENTO • MATRIZES SOCIAIS • AGÊNCIAS • ANÁLISE ESTRUTURAL DAS REDES SOCIAIS.

\section{Abstract}

This article aims to identify the network positioning of agencies that provide digital content production services in the corporate market of Rio Grande do Sul. To this end, this study conducted a structural analysis of social network, verifying the employment of strategies for: 1) centrality position; 2) intermediate position; 3) PageRank position; 4) intermediate and PageRank position; and 5) presence position.

KEYWORDS: DIGITAL ENVIRONMENTS • POSITIONING STRATEGIES • SOCIAL MATRIXES • AGENCIES • STRUCTURAL SOCIAL NETWORK ANALYSIS.

\section{Resumen}

Este artículo tuvo como objetivo identificar las estrategias de posicionamiento en la red, emprendidas por agencias que prestan servicios de producción de contenido digital en el mercado corporativo de Rio Grande do Sul (Brasil) para sus clientes. Para la metodología adoptada se utilizó el análisis estructural de las redes sociales. De ese modo, se encontraron estrategias de: 1) posición de centralidad; 2) posición de intermediario; 3) posición de mejor PageRank, 4) posición tanto de intermediario como de mejor PageRank, y 5) posición de presencia. 


\section{INTRODUÇÃO}

A pesquisa visou ao estudo das estratégias de posicionamento na rede articuladas pelas agências de comunicação digital do Rio Grande do Sul (RS) nas ambiências digitais dos seus clientes. Este cenário incide no fazer/existir/representar dos múltiplos atores sociais nas e pelas ambiências por meio dos processos comunicacionais sócio-técnico-discursivos. Assim, através dos fluxos de sentidos sobre si mesmos, sobre, com e por meio dos outros, constituem-se as matrizes sociais. A argumentação sustenta-se na dimensão individual - seu fazer/existir/representar - e na dimensão relacional - seu dizer/ publicizar -; logo, consideram-se os atores envolvidos, as ambiências digitais e os modos de atuação, que resultam em cinco posições na rede.

Consequentemente, o lócus está nos relacionamentos a partir da construção e da disputa de fluxos de sentidos que se dão através das conexões nas ambiências, as quais originam as matrizes sociais no âmbito da internet e em torno dos atores acionados. Em função dessa dinâmica, requer-se o (re)pensar do agenciamento dos atores com as ambiências digitais, no seu dizer/publicizar, reconhecendo o valor social do outro (ético-político). Tais discussões nos levam a considerar a mão-de-obra técnica das agências, que costuma intuir por experiências continuadas, e essa "fala" puramente empírica não reflexiona acerca das atuais práticas comunicacionais implicadas à lógica estrutural das redes, tampouco da constituição das matrizes sociais.

Assim, é necessária a pesquisa sobre a refiguração crítica da experiência dos indivíduos em seus relacionamentos a partir dos agenciamentos com as ambiências digitais. Tais observações nos permitem adentrar nas dinâmicas das matrizes sociais, visando compreendê-las a partir dos processos comunicacionais contemporâneos. Logo, o objetivo desse artigo é identificar as estratégias de posicionamento na rede empreendidas pelas agências de comunicação digital do RS. Para tanto, a metodologia foi alicerçada através da pesquisa empírica em comunicação, que contou com método da análise estrutural das redes sociais (ARS) (Lemieux; Ouimet, 2004), responsável pela definição do campo de estudo e do corpus.

0 campo de estudo foi delimitado às empresas-clientes que, em seus conteúdos, continham elementos tecnológicos formadores de conexões/redes - por exemplo, link contextual, @ (arroba) e \# (hashtag). Assim, no período de 2018 a 2019, 0 campo de estudo foi formado por 15 agências; 38 empresas-clientes, a partir de quatro ambientes digitais (76 sites; 18 blogs; 10 fanpages e dois canais no Youtube), um ator individual na ambiência Facebook (perfil) e um ator coletivo no Facebook (fanpage). Já o corpus foi formado por 71 conteúdos das empresas-clientes e um conteúdo de ator coletivo.

Com o intuito de buscar o desenvolvimento teórico e empírico, a construção do artigo subdividiu-se em quatro partes: a primeira apresenta a contextualização teórico-argumentativa; a segunda expõe a metodologia; a terceira revela e discute os resultados; e a quarta aborda as conclusões.

\section{REFERENCIAL TEÓRICO}

Partiu-se do núcleo teórico das matrizes sociais tramadas através dos processos comunicacionais no contexto dos ambientes digitais, pois "não são simples 'suportes' ou 'veículos' ou 'meios' técnicos, portanto, mas dispositivos, que se entendem como matrizes tecnológicas para a formação do sentido" (Sodré, 2014, p.281). Implicam os modos de ser dos múltiplos atores por meio da tecnologia, assim, segundo Sodré (2014, p.285), "o mundo tecnológico e as identidades existenciais são entidades inseparáveis: as formas tecnológicas de vida dispõem-se progressivamente como formatos existenciais" tornados concretos a partir das articulações sócio-técnicas-discursivas dos atores nas múltiplas ambiências. 
Consequentemente, os processos comunicacionais na conjuntura do quarto bios implicam reconhecer a presença de entrelaçamentos na modalidade do dizer (discurso), arquitetada dentro da lógica das redes e que, portanto, envolve também os lugares sociais das relações intersubjetivas dos múltiplos atores (sociotécnicas). Este caminho nos leva à redescrição do modo de ser dos atores nos e pelos ambientes digitais através das estratégias de posicionamento contidas nesses movimentos. Contudo, para que se possa penetrar nessa arquitetura, primeiramente, há de se compreender o universo discursivo por trás dela, visto que, dentro dessas dinâmicas, há os recursos estratégicos nos modos de "dizer", isto é, as tessituras argumentativas construídas pelo sujeito da enunciação no seu discurso de acordo com os efeitos de sentido que ele deseja acionar, o que nos encaminha para a articulação com o sociotécnico.

Essa conjuntura se funda com o processo comunicacional que constrói relações e/ou vínculos, acionados intencionalmente através de elementos tecnológicos formadores de contextos como, por exemplo, link contextual; @ (arroba); e \# (hashtag). Pois, "[...] em sua essência, propõem relações (que podem ser permanentes ou não) e/ou vínculos a partir de um ambiente e arquitetados no discurso com o acionamento de sentidos. Assim, passam a representar relações/vínculos entre os atores/ ambientes/discursos" (Lasta, 2019, p.6). Logo, esses elementos passam a estar contextualizados nos enunciados a partir dos acionamentos intencionais dos enunciadores com relação a outros, que assim encaminham os enunciatários para atores/ espaços/conteúdos pré-selecionados de forma direta ou indiretamente.

Como expõe Giddens (2003, p.105), "as relações sociais dizem respeito ao 'posicionamento' dos indivíduos dentro de um 'espaço social' de categorias e vínculos simbólicos". A posição social dentro da matriz também é a sua identidade social e está enlaçada a prerrogativas, obrigações e expectativas. No contexto tecnológico, "[...] o indivíduo é apreendido como um nó de possíveis relações, ou seja, identidade própria em função de um outro-si (nó) conectado a outros (estrutura técnica de relacionamentos)" (Lasta, 2015, p.135). Quando se articulam os discursos nos ambientes digitais, também se acionam recursos sócios e técnicos. Esse processo possui algum grau de envolvimento da consciência do enunciador, que pode ser desde um nível básico/médio até um mais complexo, o que requer a compreensão das formações relacionais/vinculativas na rede, isto é, as implicações das redes sociais enquanto matrizes sociais.

Toda essa estrutura inicia-se com a operacionalização das escolhas a serem exercidas pelos múltiplos atores nos e pelos seus ambientes digitais, e é, então, concretizada nas produções dos seus conteúdos. Assim, as matrizes sociais vão para além da questão tecnológica (de rede), uma vez que elas também representam as formações dos sentidos, pois adentram nos aspectos individuais dos atores (aqui representados por cinco macroáreas). Assim, as matrizes sociais tratam de dar luz à tecnologia articulada com a identidade existencial dos múltiplos atores, tomando concretude por meio dos conteúdos produzidos, que estão implicados em discursos (modalidades do dizer) dentro de uma lógica de rede, a qual envolve os lugares sociais tecnológicos dos atores. Em consequência, conduz-nos às possíveis estratégias de posicionamento por meio da ARS.

\section{METODOLOGIA}

A metodologia fundamentou-se na pesquisa empírica em comunicação ao considerar a íntima relação entre a teoria e 0 empírico. Foi operacionalizada através do método da ARS (Lemieux; Ouimet, 2004), logo, as observações recaem na estrutura das redes sociais desenvolvidas por esses múltiplos atores a partir dos processos comunicacionais em diferentes ambientes digitais (nas construções discursivas com elementos sociotecnológicos).

Para delimitar o campo de estudo, inicialmente verificaram-se as 63 empresas que compõem a Associação Brasileira dos Agentes Digitais (ABRADi-RS), pois ela é responsável por representar as principais empresas gaúchas que se encontram inseridas no ramo de negócios digitais. Além disso, visa criar, no mercado corporativo do RS, uma cultura envolta ao contexto digital. Como 
a referida associação estabelece compromisso com a cultura digital, acredita-se, consequentemente, que os seus associados também o façam. Então, ao verificar-se os portfólios dessas agências, isto é, as empresas-clientes que elas atendem, chegou-se ao campo de estudo de 15 agências e 38 empresas-clientes em sites (76); blogs (18); fanpages(10); YouTube (2), um ator individual no Facebook (perfil) e um ator coletivo no Facebook (fanpage). Esses múltiplos atores se apropriavam de/utilizavam elementos tecnológicos formadores de contextos e, consequentemente, construíam e/ou estavam inseridos dentro da rede.

Já o corpus foi formado por 71 conteúdos das empresas-clientes e por um conteúdo de ator coletivo, pois esses continham elementos tecnológicos formadores de contextos, que são os responsáveis pelas construções das redes e nos possibilitam a execução da ARS. Consequentemente, foram demarcados, considerando os atores, as ambiências, os conteúdos com esses elementos tecnológicos dos atores das empresas-clientes e dos demais múltiplos atores sociais em suas respectivas ambiências e conteúdos.

Essa construção da delimitação do campo e do corpus leva em consideração os princípios das matrizes sociais, conforme demonstra a Figura 1, a seguir. Nela, é permitido que qualquer múltiplo ator esteja na posição principal e, consequentemente, reordenam-se continuamente as matrizes sociais nessa arquitetura.

Figura 1: Matrizes sociais por meio da mediação estratégica comunicacional com ambiências digitais

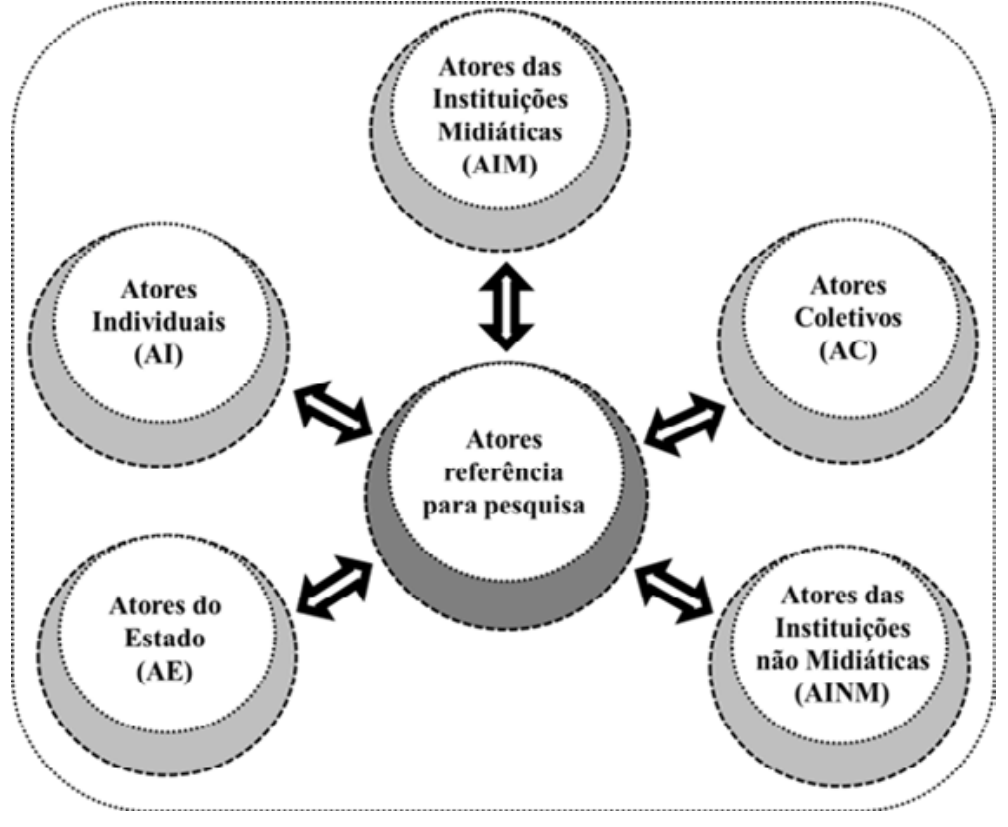

Fonte: elaborada pela autora.

A intenção é tornar visível a dinâmica implicada no contexto das matrizes sociais. Assim, encontram-se os círculos "porosos" que equivalem aos ambientes digitais, nos quais os atores estão agenciados; no centro, os atores a serem postos como referência no estudo; já as setas correspondem às relações e/ou vínculos entre esses múltiplos atores; e a "porosidade" representa a simbiose entre 0 ator e 0 ambiente digital.

Assim, ao se agenciarem, os atores exteriorizam-se por meio dos seus ambientes, nos quais constroem os seus próprios "espaços" de "fala/atuação". Logo, são separados em cinco macroáreas, a partir das proposições contidas nas suas ambiências, conforme salienta Lasta (2017, p.213):

1ำ - Atores das instituições não midiáticas (AINM): contexto organizacional, voltadas ao público externo e reconhecidas pela organização; entretanto, não têm razão em/de ser na atividade midiática. $2^{0}$ - Atores das instituições midiáticas (AIM): correspondem ao agenciamento desses com as mais variadas ambiências digitais, nas quais encontramos as lógicas e operações relativas ao campo dos media, pois estes possuem razão em/de ser na atividade midiática. $3^{0}$ - Atores do Estado (AE): [...] contexto relativo [...] 
ao executivo, legislativo e judiciário. $4^{0}$ - Atores individuais (Al): [...] contexto individual, isto é, relativos à área da sociedade civil. 5- - Atores coletivos (AC): [...] contexto das organizações não governamentais e sem fins lucrativos [...]

Ou seja, aqui se dá a apreensão da dimensão individual (representação do ator no seu ambiente digital) e também a dimensão relacional (as matrizes sociais) que o percurso metodológico a seguir nos permitiu pesquisar.

A lógica está implicada no lugar social das interações intersubjetivas dos múltiplos atores que estão agenciados com os ambientes digitais. 0 ator está exteriorizado nesse espaço, que lhe pressiona para fora de si, o divide e o impele a relacionar-se com os demais múltiplos atores. Assim, ao fazer uso dos elementos tecnológicos formadores de contextos, sua exterioridade passa a estar posta em relação com outrem, dividindo-o entre o individual e o social. Consequentemente, a montagem da lógica por trás dos posicionamentos estratégicos dos múltiplos atores, dentro das matrizes sociais, pode ser articulada por meio da ARS.

A ARS, como descrevem Lemieux e Ouimet (2004), engloba três processos: 1) o processo descritivo; 2) o processo explicativo de primeiro nível; e 3) o processo explicativo de segundo nível.

1) No processo descritivo, há as determinações (Recuero, 2011): a) os atores (que são os nós da rede na ARS), neste estudo, delimitaram-se as 38 empresas-clientes e os demais múltiplos atores com os quais elas se relacionaram; $b$ ) as conexões como multiplexas; c) o grau de conexão a partir de um grau; por meio do qual se traçou a conexão a partir de um ator (nó) e se representaram as suas conexões (outdegree indegree). Realizou-se, então, a coleta de dados, que se deu de 2018 a 2019 e teve como corpus 72 conteúdos. Escolheu-se como forma de representação o sociograma, realizado através de um grafo no qual as linhas são as conexões e os pontos são os atores. 0 sociograma representa graficamente as redes e foi gerado com o NodeXL.

2) No processo explicativo de primeiro nível, há a explicação em primeiro nível, na qual os dados empíricos são descritos e ocorre a explicação acerca do grafo (resultado dos dados coletados) através dos conceitos principais relativos à ARS (Lemieux; Ouimet, 2004), os quais foram selecionados:

a) Centralidade de grau (indegree e outdegree): essa medida trata das atividades relacionais e é utilizada para medir o número de conexões diretas de cada ator em um grafo. Assim, identifica as conexões que um nó recebeu (indegree) e as conexões que ele fez (outdegree) e determina se o ator é mais central, ou seja, caso possua maior número de conexões diretas com outros atores.

Essa medida incidirá na posição dos atores na rede, que pode ser:

- Dominante: caso o ator seja emissor de uma conexão com outros atores em um determinado conjunto de atores;

- Dominada: caso o ator não seja emissor de nenhuma uniconexão (caminho em sentido único) com outro ator em um determinado conjunto de atores em que há pelos menos um ator dominante;

- Semidominante: caso o ator não seja ocupante de uma posição de dominante e mesmo assim seja emissor de uma uniconexão para um ou vários outros atores e também seja destinatário de uma uniconexão de um ou vários atores;

- Subdominante: caso o ator esteja em um conjunto de atores em que não há atores dominantes e também não se encontre na posição semidominada e seja emissor de uma uniconexão com um ou vários atores;

- Subdominada: caso o ator esteja em um conjunto de atores em que não há atores dominantes e também não seja emissor de nenhuma conexão com outro ator, mas é destinatário de uma uniconexão de algum outro ator;

- Isolada: caso o ator não seja nem emissor nem destinatário de outro ator.

Essas posições dos atores na rede incidem nos tipos de conexão: 
- Conexidade forte: ocorre quando os atores são dominantes; assim, há conexão com cada um dos atores;

- Conexidade semiforte: ocorre quando há pelo menos um ator dominante e quando há conexão em algum sentido entre os pares de atores; desse modo, há pelo menos um buraco estrutural;

- Conexidade quase forte: acontece quando há pelo menos um ator dominante e é emissor, mas não é destinatário de ninguém; assim, também há um buraco estrutural;

- Não conexidade: ocorre quando um ou vários atores se encontram isolados; assim, sem a existência de ator dominante.

Essas posições dos atores na rede, atrelados aos tipos de conexão, incidem na tipologia dos grafos:

- Grafo fortemente conexo: nesse caso, a estrutura relacional dos atores encontra-se como de colegial;

- Grafo semifortemente conexo: nesse caso, a estrutura relacional dos atores encontra-se como estratificada;

- Grafo quase fortemente conexo: nesse caso, a estrutura relacional dos atores encontra-se hierarquizada;

- Grafo não conexo: nesse caso, a estrutura relacional dos atores encontra-se desintegrada.

b) Centralidade de intermediariedade (betweenness centrality): essa medida reflete a importância da posição intermediária de um ator no grafo, que assegura ao ator o papel de ser coordenador e/ou controlador da rede. Assim, pressupõe que, quanto mais um ator encontra-se na posição intermediária, mais capacidade de coordenar terá em relação aos demais.

c) PageRank. mede o ranqueamento de cada nó/vértice no grafo e está intrínseco à visibilidade dos atores na rede. Encontrase correlacionado com as medidas de indegree, outdegree e betweenness centrality.

3) No processo explicativo de segundo nível, há o processo de pôr em "diálogo" os dados coletados e postos à explicação (no primeiro nível) com as teorias referentes a esta pesquisa, que, neste caso, especificamente, se trata da teoria da coordenação das relações (Lemieux; Ouimet, 2004) atrelada à contextualização teórica-argumentativa do artigo.

A teoria da coordenação das relações (Lemieux; Ouimet, 2004) estabelece que a coordenação pressupõe estruturação conexa das relações, que podem ser de: conexidade forte; conexidade semiforte; ou conexidade quase forte, sendo impossível em uma rede não conexa. Contudo, para que se possa estabelecer os tipos de conexão, há de se investigar as posições dos múltiplos atores, que podem ser: dominante; dominada; semidominante; subdominante; subdominada; e isolada. Esse caminho implica a explicação das estruturações relacionais assumidas nas matrizes sociais através das medidas de centralidade de grau (indegree e outdegree); de centralidade de intermediariedade (betweenness centrality); e do PageRank. Ao se promover esse percurso metodológico, identificam-se quatro estratégias de posicionamento dentro das estruturações das matrizes sociais entre os múltiplos atores, que transformaram seus ambientes digitais em espaços sociais por meio dos processos comunicacionais.

\section{RESULTADOS}

Buscou-se identificar as estratégias de posicionamento na rede empreendidas pelas agências de comunicação digital no RS a partir das ambiências digitais dos seus clientes, pois acredita-se que as matrizes sociais, nesse contexto digital, ocorrem por meio dos acionamentos dos múltiplos atores a partir dos ambientes digitais nos quais eles constroem seus discursos. Logo, o que nos motivou foram as construções discursivas que acionavam outros múltiplos atores através da potencialidade sociotécnica de cada ambiência, ou seja, interessamo-nos pelas constituições de relações e/ou vínculos que se dão de forma intencional dentro dos discursos desses múltiplos atores nos seus ambientes. 
Consequentemente, entendeu-se que podem gerar matrizes sociais - isto é, não as originam automaticamente - ao propor a sua construção como procedente de outrem e/ou o dizer de outrem para construir o seu próprio dizer. Assim, as matrizes sociais aqui apreendidas estabelecem a experiência do ator em composição com a experiência do outro através de interrelação entre os atores, ambientes e discursos. Para tanto, aplicou-se a ARS (Lemieux; Ouimet, 2004).

No primeiro nível operacional concernente ao processo descritivo (Recuero, 2011), elaborou-se o Quadro 1 para especificar os atores e ambientes a partir das formas e cores a serem visualizados no grafo 1.

Quadro 1: Especificação dos nós/vértices

\begin{tabular}{|c|c|c|c|}
\hline Forma & Cor & Ator & Ambiência \\
\hline Triângulo & Rosa & $A C$ & Site \\
\hline Triângulo & Preto & AINM & Site \\
\hline Triângulo & Azul & AIM & Site \\
\hline Triângulo & Vermelho & $A E$ & Site \\
\hline Diamante & Vermelho & $\mathrm{AE}$ & Arquivo \\
\hline Círculo & Rosa & $A C$ & Fanpage \\
\hline Círculo & Verde & $\mathrm{Al}$ & Fanpage \\
\hline Círculo & Preto & AINM & Fanpage \\
\hline Círculo & Azul & AIM & Fanpage \\
\hline Círculo fechado & Verde & $\mathrm{Al}$ & Linkedln \\
\hline Disco & Preto & AINM & Blog \\
\hline Esfera & Azul & AIM & YouTube \\
\hline Quadrado & Preto & AINM & Instagram \\
\hline
\end{tabular}

Fonte: elaborado pela autora.

A partir dessas especificações, encontrou-se o seguinte contexto:

- os cinco tipos de macroáreas referentes aos múltiplos atores;

- um total de 822 atores (nós/vértices);

- 810 laços únicos.

A fim de representar essa conjuntura, criou-se o grafo 1 a partir do algoritmo Harel-Koren Fast Multiscale, que possibilitou a visualização das redes sociais por meio do agrupamento de clusters. 
Grafo 1: Inter-relações dos múltiplos atores a partir do algoritmo Harel-Koren Fast Multiscalel

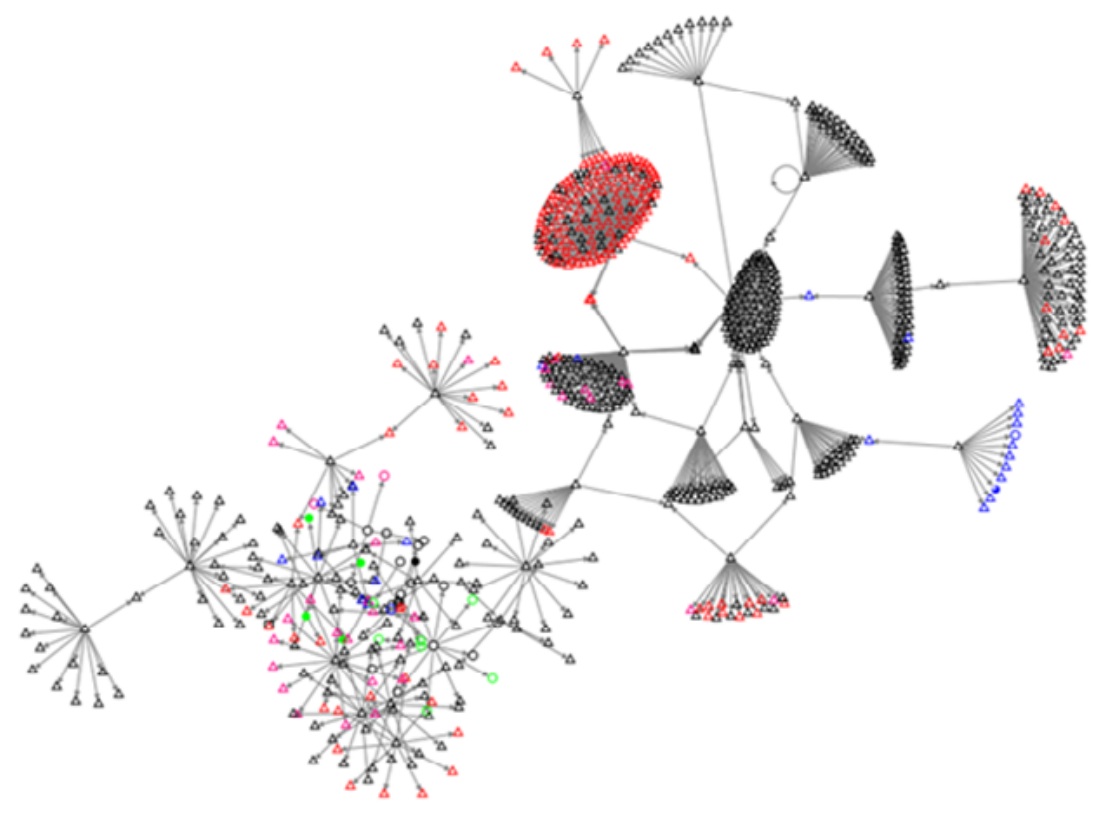

Fonte: elaborado pela autora.

Assim, no processo explicativo de primeiro nível (Lemieux; Ouimet, 2004), adentrou-se na estrutura com a seguinte dinâmica:

- 96,58\% dos elementos tecnológicos formadores de contextos foram realizados para sites;

- 2,44 para fanpages e as demais ambiências tiveram menos de $1 \%$.

Sobre os tipos de atores que entraram em relação através das ambiências digitais, tem-se que:

- 67,16\% foram entre atores das instituições não midiáticas a partir de 65,81\%, sites, 1,22\%, fanpages e 0,12\%, Instagram;

- 23,32\% para atores do estado através de $23,2 \%$, sites;

- 4,52\% para atores coletivos por meio de 4,27\%, sites e 0,24\%, fanpages,

- 3,66\% para atores das instituições midiáticas a partir de 3,3\%, sites, 0,24\%, fanpage, 0,12\%, YouTube e Instagram;

-1,34\% para atores individuais através de 0,85\% fanpage e 0,49\%, Linkedln.

Logo, pode-se perceber que as relações foram estabelecidas majoritariamente entre empresas-clientes com seus clientesempresas, mas também entre empresas-clientes com as demais quatro macroáreas, contudo, ambos sem reciprocidade, havendo apenas uma exceção que se deu por meio de processo de reconhecimento entre ator da instituição não midiática com ator coletivo no Facebook entre fanpages, em função de parceria a partir de uma série de projetos. A hipótese levantada acerca desses achados diz respeito à natureza da produção dos conteúdos ser de ordem institucional em quase sua totalidade nos ambientes digitais das empresas-clientes do campo de estudo. Todavia, essa conjuntura também incita que há um fecundo mercado relacional com os demais múltiplos atores e ambiências a ser explorado.

Ao se aprofundarem as relações formadoras de matrizes sociais, identificaram-se 34 agrupamentos diferentes através da articulação entre o algoritmo Harel-Koren Fast Multiscale e o subalgoritmo Clauset-Newman-Moore. Os agrupamentos foram separados de acordo com o direcionamento de suas forças dentro da matriz social como um todo (estão separados pelas cores no grafo 2).

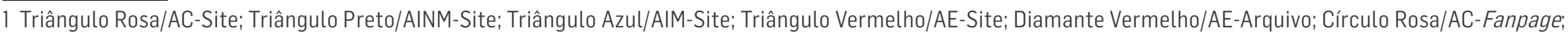

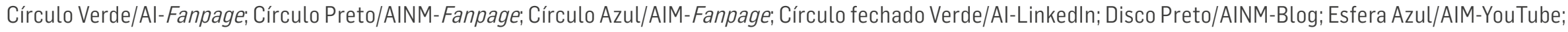
Quadrado Preto/AINM - Instagram. 
Grafo 2: Inter-relações dos múltiplos atores a partir do algoritmo Harel-Koren Fast

Multiscale articulado ao subalgoritmo Clauset-Newman-Moore

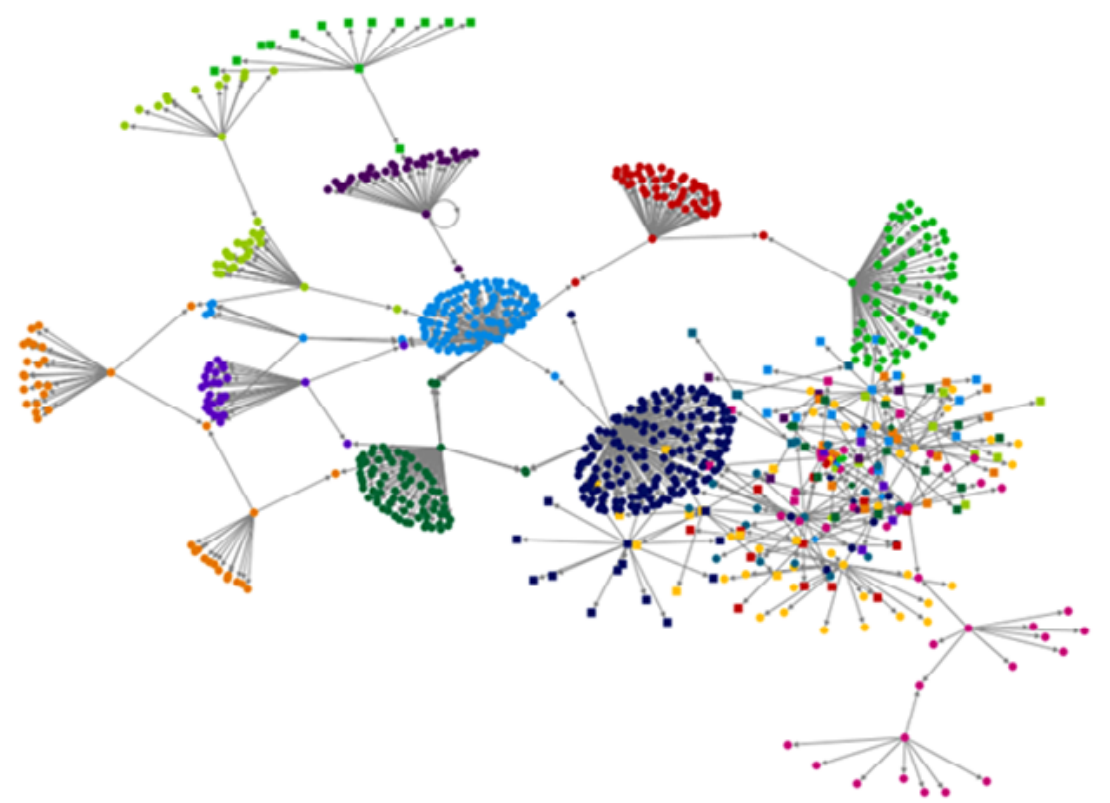

Fonte: elaborado pela autora.

Assim, encontraram-se as 34 micro matrizes sociais em torno das relações estabelecidas com os atores constituintes do campo de pesquisa, que foram originadas através das conexões entre os atores e auxiliam-nos a encontrar as posições dos múltiplos atores. Ou seja, encaminham-nos à análise do grau de conexão entre os atores, que trata das conexões que um nó recebeu (indegree) e das conexões que ele fez (outdegree). Assim, observou-se que os atores que receberam mais de uma conexão (indegree), representados em vermelho no grafo 3, não realizaram conexões (outdegree) a outros atores.

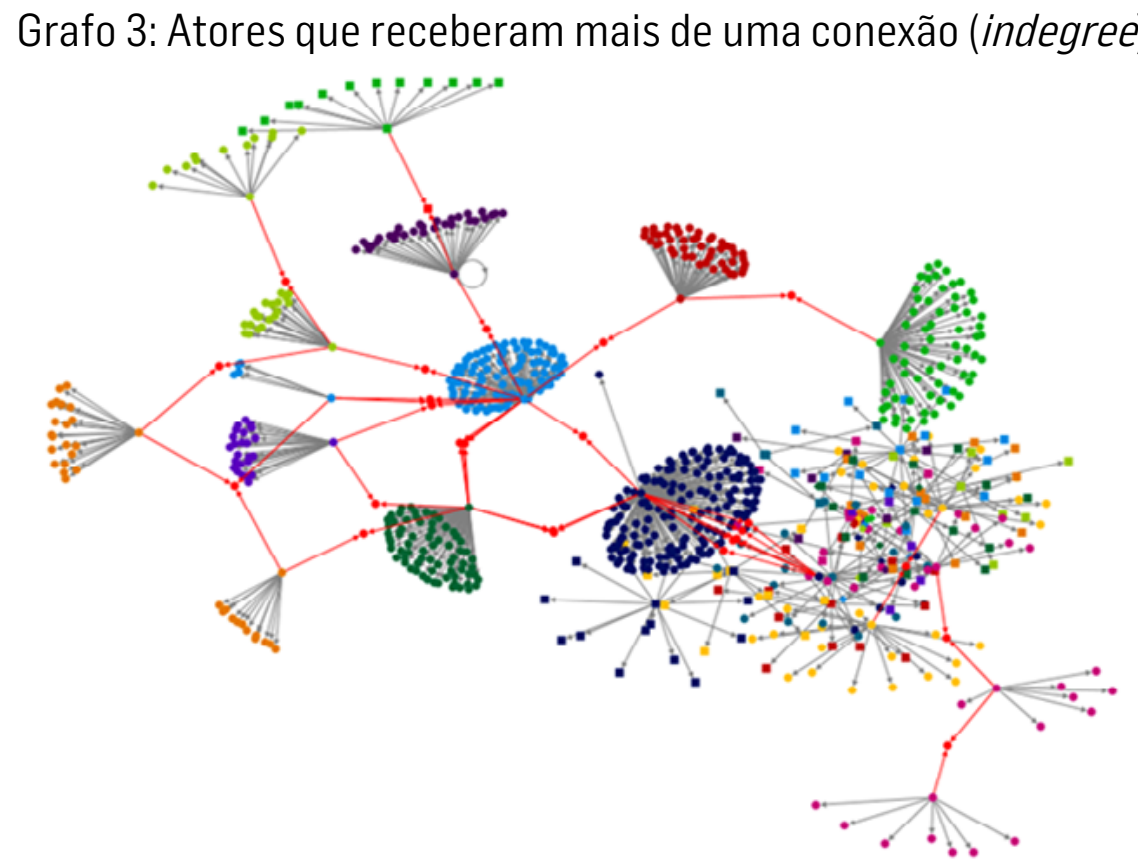

Fonte: elaborado pela autora.

Consequentemente, os atores destacados em vermelho no grafo 3 encontram-se em uma posição dominada, pois não são emissores de nenhuma conexão com outro ator e estão inseridos em um conjunto de atores em que há atores dominantes. Já no que se refere aos atores que fizeram conexões (outdegree) a outros atores, percebeu-se que não receberam nenhuma conexão (indegree), à exceção do ator que realizou conexões (outdegree) e recebeu uma conexão (indegree), ambos os casos estão em posição dominante, uma vez que são emissores de conexões com outros atores em um determinado conjunto de atores e são ocupantes da posição de dominante. 
Com estas observações, pôde-se concluir que a reciprocidade relacional dos atores envolvidos nessa pesquisa é incipiente, pois os atores que fazem conexões (outdegree) não recebem conexões (indegree) e vice-versa, havendo somente um caso que, consequentemente, considerou-se como exceção. Em consequência, o tipo de conexão encontrado nessa matriz é de ordem semiforte forte, visto que, nas micro matrizes em que há atores dominantes também há conexão, em algum sentido, entre os pares de atores. Logo, o grafo é semifortemente conexo. Sendo assim, a estrutura relacional dos atores encontra-se como estratificada.

No que se refere à centralidade de intermediariedade (betweenness centrality) dos atores, que trata da importância da posição dos atores no grafo, isto é, quanto mais um ator se encontrar em posição de intermediariedade, mais capacidade relacional ele terá com os demais, assim, terá papel de coordenação e controle das relações. Destacou-se em vermelho, no grafo 4, os dez atores com maior valor de intermediariedade.

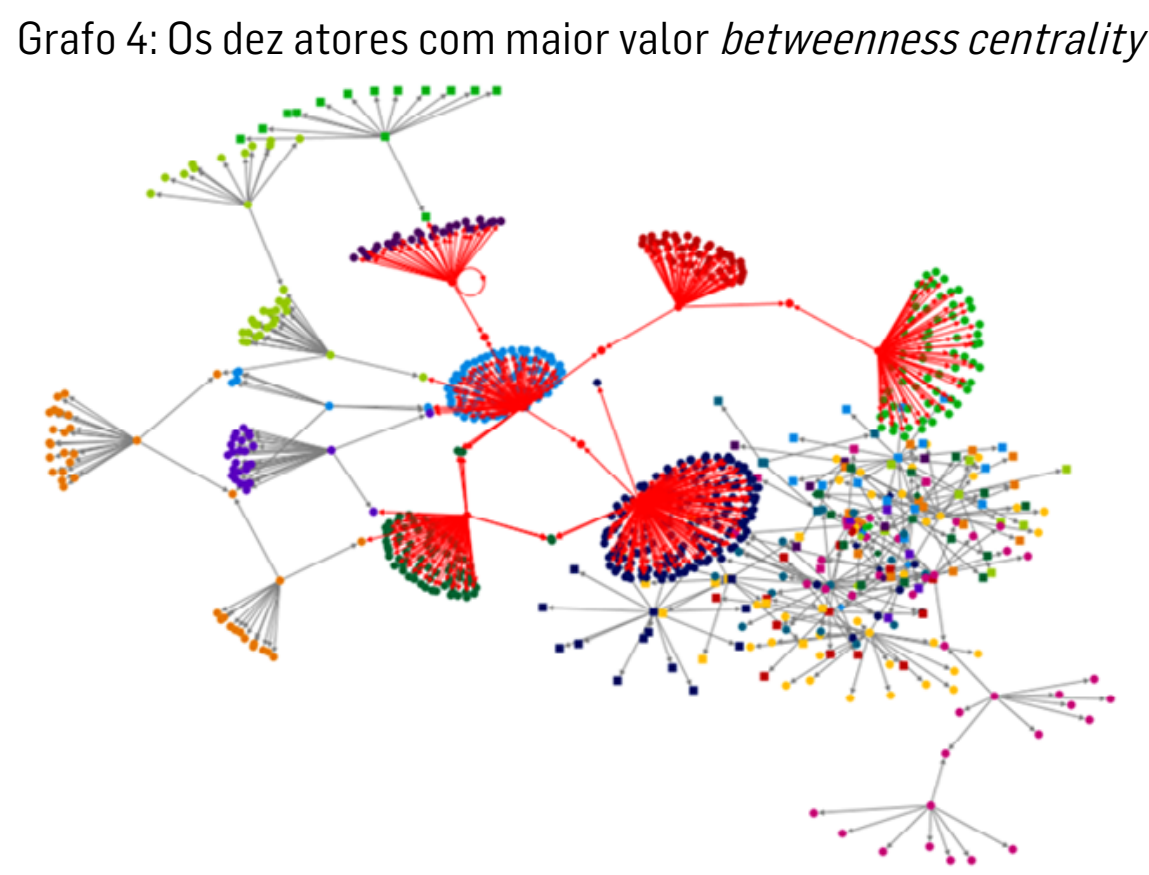

Fonte: elaborado pela autora.

Através das marcações em vermelho - isto é, dos dez atores em melhor posição de intermediariedade -, percebe-se que há tanto atores com maior número de conexões feitas quanto atores que receberam conexões. Consequentemente, infere-se que a posição de intermediariedade não depende somente da quantidade de conexões realizadas, mas também da importância desse ator que faz conexões com os demais na rede. Logo, mesmo que um ator faça poucas ou nenhuma conexão, ele poderá estar em posição intermediária na rede, pois torna-se um nó capaz de relacionar-se com os demais atores que estão fazendo conexão a ele. Desse modo, pode-se pressupor que, se esse ator recebe conexão de dois ou mais atores, ele é de interesse para ambos, consequentemente, pode ser ponte para uma futura conexão. Em contraponto, há o PageRank², que mede a importância de cada ator no grafo; logo, está intrínseco à visibilidade dos atores. Os dez atores com melhor PageRank encontram-se marcados em vermelho no grafo 5.

2 De acordo com software NodeXL, o algoritmo utilizado para essa métrica trata-se da análise de links, desenvolvida por Larry Page. 


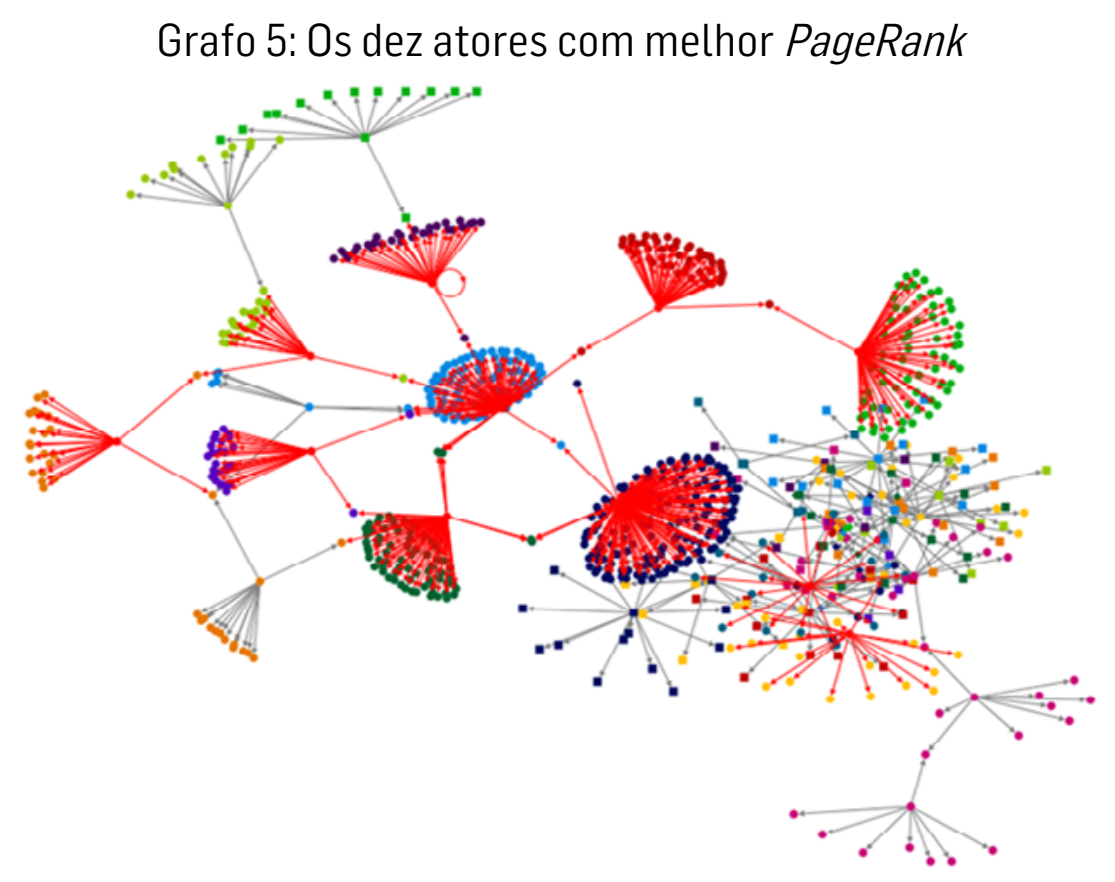

Fonte: elaborado pela autora.

Percebe-se que os atores com melhor PageRankpossuem correlações entre as medidas referentes ao conceito de centralidade dos atores (indegree; outdegree; betweenness centrality). Logo, os dez melhores não são necessariamente os mesmos que se encontram como os dez principais intermediários, pois a visibilidade do ator, nesse caso, está correlacionada à quantidade de conexões que ele faz conjuntamente com a posição do ator ao qual este fez conexões.

A partir de tais constatações, adentrou-se no processo explicativo de segundo nível (Lemieux; Ouimet, 2004) por meio da coordenação das relações, na qual a escolha do ator para se relacionar é imprescindível, isto é, a busca de relações com atores em zonas estratégicas na rede. Assim, quanto maior a proximidade, há independência (evita o controle dos outros), e quanto maior a intermediação, mais controle sobre os outros na matriz social. Sendo assim, verificou-se que, dentre os atores analisados, havia estratégias de posicionamento voltadas para:

1. posição de centralidade, ou seja, para a obtenção de independência - ocorre quando se encontra engajado em muitas relações;

2. posição de intermediário, isto é, para obtenção de controle sobre as relações - acontece quando se encontra como "ponto de passagem" entre os atores;

3. posição de melhor PageRank para obtenção de visibilidade na rede - dá-se quando se encontra engajado em relações e/ ou com atores com representatividade na rede;

4. posição tanto de intermediário como de melhor PageRank-ocorre quando se encontra engajado em relações com atores de representatividade na rede;

5. posição de presença - acontece quando se encontra com poucas relações e/ou com atores de pouca representatividade na rede.

As práticas encontradas nos ambientes das empresas-clientes que constituem o portfólio das agências do campo de estudo continham as cinco estratégias de posicionamento. Entretanto, na maioria dos casos estudados, as empresas-clientes encontravam-se sob uma perspectiva de estratégia de presença na internet, uma vez que o processo de reconhecimento 
não ocorre de forma recíproca (indegree e outdegree) e os acionamentos relacionais deram-se na perspectiva tecnológica e não sociodiscursiva, isto é, os acionamentos e as construções discursivas realizadas pelas agências aos seus clientes pouco consideraram a relevância de posição dos atores a se relacionar na rede, resultando, consequentemente, em uma estratégia voltada somente para a presença da empresa-cliente naquelas ambiências e na rede, logo, nas matrizes sociais.

\section{CONSIDERAÇÕES FINAIS}

Com a ARS através de suas medidas, conseguiu-se apreender cinco estratégias de posicionamento, por meio das quais constatou-se empiricamente a dinâmica envolta nesse processo na internet. Assim, por meio dessa observação técnica, que representa a refiguração das experiências dos múltiplos atores sociais em suas ambiências digitais, mostrou-se que as perspectivas relacionais ainda se encontram incipientes, tendo em vista que o fazer/existir/representar por meio do saber dizer/publicizar das empresas-clientes das agências do campo de estudo estava voltado majoritariamente para uma estratégia que não preza pela construção e manutenção de relações/vínculos, logo, impactando as matrizes sociais.

Percebeu-se que os conteúdos das agências estudadas pouco consideraram a lógica estrutural das redes. Consequentemente, seu posicionamento de presença teve maior incidência frente às outras estratégias. Não se julgou uma como melhor do que a outra e, mesmo que não se tenha conhecimento técnico acerca do funcionamento e da ARS, se fossem aprendidas as estratégias de posicionamento, considerando as lógicas das matrizes sociais, poder-se-ia propor posicionamentos para além da presença das empresas-clientes na internet, uma vez que os posicionamentos estão atrelados a estar: engajado em muitas relações; no "ponto de passagem" entre os atores; e engajado em relações com atores com representatividade na rede.

Em contrapartida, tanto as agências como as empresas-cliente e demais múltiplos atores estariam concebidos como valor social de si mesmos e dos outros, ou seja, atores em seus estados individuais e sociais. Assim, conhecer-se-iam as redes sociais como matrizes a partir das construções discursivas sociotécnicas, pois envolveriam o elemento tecnológico formador de conexões - links; @ (arroba); \# (hashtag) -, também o sócio - quem é o ator e onde ele se encontra na rede - e o discursivo - ator articulado "dentro" da argumentação -, o que resultaria na ampliação das possibilidades estratégicas de posicionamento na internet para além da presença.

\section{REFERÊNCIAS}

GIDDENS, Anthony. A constituição da sociedade. São Paulo: Martins Fontes, 2003.

LASTA, Elisangela. A práxis reflexiva das relações públicas na sociedade midiatizada: mediação estratégica comunicacional nos blogs corporativos. 2015. Tese (Doutorado em Comunicação) - Programa de Pós-Graduação em Comunicação, Universidade Federal de Santa Maria, Santa Maria, 2015.

LASTA, Elisangela. Metodologia na pesquisa empírica em comunicação organizacional digital: estratégias sócio-técnicadiscursivas. In: CONGRESSO BRASILEIRO CIENTÍFICO DE COMUNICAÇÃO ORGANIZACIONAL E DE RELAÇÕES PÚBLICAS, 13., 2019, São Paulo. Anais [...]. São Paulo: Abracorp, 2019.

LASTA, Elisangela. Práxis das relações públicas ética-política-estética: uma perspectiva para a hexis educativa na sociedade midiatizada. Revista Internacional de Relaciones Publicas, Málaga, v.7, n.14, p.207-226, 2017. 
LEMIEUX, Vicent; OUIMET, Mathieu. Análise estrutural das redes sociais. Lisboa: Instituto Piaget, 2004.

RECUERO, Raquel. Estudos de redes sociais. In: AMARAL, Adriana; FRAGOSO, Suely; RECUERO, Raquel. Métodos de pesquisa para internet. Porto Alegre: Sulina, 2011. p.115-138.

SODRÉ, Muniz. A ciência do comum: notas para o método comunicacional. Petrópolis: Vozes, 2014.

Artigo recebido em 21.04.2021 e aprovado em 05.07.2021. 